\title{
Extrusion of Intrastromal Corneal Ring Segments in Keratoconus; How to Avoid?
}

\author{
Amr Mounir* \\ Department of Ophthalmology, Sohag University, Egypt
}

*Corresponding author: Amr Mounir, Department of Ophthalmology, Sohag

University, Egypt.

Received Date: November 28, 2018

Published Date: January 22, 2019

\section{Introduction}

Implantation of intrastromal corneal ring segments (ICRS) is an effective and reversible refractive procedure for keratoconus management [1]. the main advantages of ICRS in treatment of keratoconus are safety, reversibility and stability [2,3]. Ring segments extrusion is one of the postoperative complications of ICRS implantation which leads to ring explantation [4].

\section{Causes and Predisposing Factors}

Ring extrusion is one of the most common complications of ICRS implantation; extrusion is associated with melting and vascularization [5]. many causes have been implicated as an etiology including ring segment migration and corneal melting which precede full ring segment extrusion [6].

\section{Technique of Tunnel Creation and Extrusion}

Ring tunnel creation by mechanical dissection showed more common extrusion than tunnel creation performed by femtosecond laser (FS) [7]. The mechanism of ring extrusion is still unclear but spontaneous focal severe thinning with biomechanical stress effect on the stroma induced by the ring segment and ocular surface dryness [8]. Lastly, chronic eye rubbing in cases of ocular allergy may be a predisposing factor.

\section{Effects of Ring Segments Extrusion}

Ring segment explanation due to extrusion results in worsening of corneal topography indices due to loss of the flattening effect of rings [9]. however; Recently, preserved topographic effect have been reported after explanation of ICRS in patients with keratoconus who had undergone corneal collagen crosslinking in the same-day at the time of ICRS implantation [10] (Figure 1).

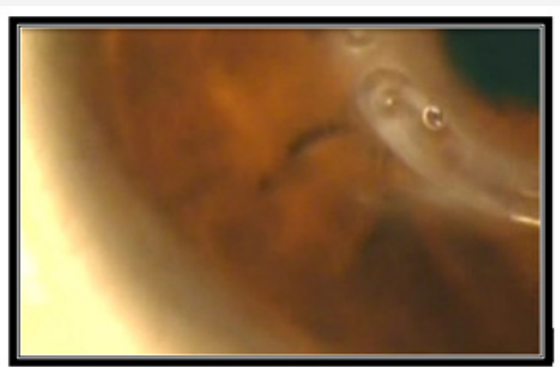

Figure 1: A case of ring segment extrusion.

\section{How to Avoid?}

The use of the FS laser in corneal tunnel creation is an effective technique to avoid late ring segment extrusion as it made the corneal ring implantation operation faster, easier, and safer with precise depth of implantation [11]. this procedure avoids rough ring implantation in mechanical dissection which may lead to inaccurate ring segment depth.

\section{Conclusion}

Intrastromal corneal ring segments extrusion is one of the common complications of ring segments implantation in keratoconus management, extrusion leads to loss of ring segments flattening effect, FS laser tunnel creation together with normal ocular surface can lead to decrease the occurrence of this complication.

\section{Acknowledgment}

None. 


\section{Conflicts of Interest}

No conflicts of interest.

\section{References}

1. Fleming JF, Wan WL, Schanzlin DJ (1989) The theory of corneal curvature change with the Intrastromal Corneal Ring. CLAO J 15(2): 146-150.

2. Colin J, Cochener B, Savary G, Malet F, Holmes Higgin D (2001) INTACS inserts for treating keratoconus: one-year results. Ophthalmology 108(8): 1409-1414.

3. Alio JL, Artola A, Hassanein A, Haroun H, Galal A (2005) One or 2 Intacs segments for the correction of keratoconus. J Cataract Refract Surg 31(5): 943-953.

4. Kanellopoulos AJ, Pe LH, Perry HD, Donnenfeld ED (2006) Modified intracorneal ring segment implantations (INTACS) for the management of moderate to advanced keratoconus; efficacy and complications. Cornea 25(1): 29-33.

5. Ferrer C, Alió JL, Montañés AU, Pérez-Santonja JJ, Del Rio MA, et al (2010) Causes of intrastromal corneal ring segment explantation: clinicopathologic correlation analysis. J Cataract Refract Surg 36(6): 970-977.
6. Mounir A, Radwan G, Farouk MM, Mostafa EM (2018) Femtosecondassisted intracorneal ring segment complications in keratoconus: from novelty to expertise. Clin Ophthalmol 12: 957-964.

7. Zare MA, Hashemi H, Salari MR (2007) Intracorneal ring segment implantation for the management of keratoconus: safety and efficacy. J Cataract Refract Surg 33(1): 1886-1891.

8. Nguyen N, Gelles JD, Greenstein SA, Hersh PS (2018) Incidence and associations of intracorneal ring segment explantation. J Cataract Refract Surg. pp: S0886-3350(18): 30856-30863.

9. Oatts JT, Savar L, Hwang DG (2017) Late extrusion of intrastromal corneal ring segments: A report of two cases. Am J Ophthalmol Case Rep 8: $67-70$.

10. Yeung SN, Lichtinger A, Ku JY, Kim P, Low SA, et al. (2013) Intracorneal ring segment explantation after intracorneal ring segment implantation combined with same-day corneal collagen crosslinking in keratoconus. Cornea 32(12): 1617-1620.

11. Ertan A, Bahadir M (2007) Topography-guided vertical implantation of Intacs using a femtosecond laser for the treatment of keratoconus. J Cataract Refract Surg 33(1): 148-151. 